\title{
DESIGN AND ANALYSIS OF ADVENTUROUS TADPOLE CONFIGURATION VEHICLE IN CONTEXT OF NEPAL
}

\author{
Nitesh Kumar Yadav \\ Department of Mechanical Engineering, \\ Kathmandu University, Dhulikhel, Nepal \\ Sujan Shrestha \\ Department of Mechanical Engineering, \\ Kathmandu University, Dhulikhel, Nepal
}

\author{
Bishnu Pandey \\ Department of Mechanical Engineering, \\ Kathmandu University, Dhulikhel, Nepal \\ Suman Bikram Bam \\ Department of Mechanical Engineering, \\ Kathmandu University, Dhulikhel, Nepal
}

\begin{abstract}
Congested roads demand for more compact vehicle in many underdeveloped countries like Nepal. Three wheeled vehicle can be a solution since, they offer great directional control, simple manufacturing and less fuel consumption but the most critical instability associated with such vehicles is the possibility of roll over during cornering. In this paper, tilt control suspension positioning is included which increases the critical cornering speed and reduces the chances of roll over by increasing track width of the vehicle. Similarly the feasibility test using $\mathrm{BC}$ test shows that it is very much feasible in Nepal.
\end{abstract}

Keywords: Vehicle Dynamics, Critical Velocity, Three-wheeled Vehicle, Tilting Mechanism.

\section{INTRODUCTION}

Bad traffic condition and boring travel experiences are results of uncontrolled population growth and their inclination toward automobile which will certainly increase in upcoming years. The in trend vehicle in present will be too big for congested traffic. A better way of solving this problem in financially poor and developing countries will be introduction of trike. Tilting wheel mechanism which carries advantages of 4 Wheelers and eliminates the drawbacks of 2 wheelers (Mukherjee, S.,Mohan, D., \& Gawade, T.R, 2007). There wheeled vehicle have many advantages over four wheelers and can give good competition to four wheelers and even overthrow them in aspect of their smallness, simple manufacturing, and low rolling resistance, fuel consumption and so on. This type of vehicle combine comfort of 4 wheelers to functionality of motor bike tilting three-wheeler is a three -wheeled vehicle whose body and or the direction of the turn. It is the most Common leaning multi-wheeler type. Such vehicles can corner safely and comfortably despite having a narrow track (N. A. El-Esnawy and J. F. Wilson, 2015). These types of vehicles have several advantages like, better directional stability, increased comfort, reduced wheel slippage, better stopping power.

\section{METHODOLOGY}

\subsection{Problem Analysis:}

Since every product face some problem along with its advantages. The main problems faced by three wheeled tadpole configuration vehicle without ant tilting mechanisms are:

- Trikes are simply more prone to tipping over than four wheel cars'.

- Three wheeled cars, with one less wheel to provide support, carry an increased possibility of rollover in a corner.

- Slippage of tires can be seen in trikes due to low traction.

\subsection{Engineering Analysis}

Initially the frame design was adopted from an already existing trike fabricated in Kathmandu University and minor changes were made to suite our purpose. The chassis is design best suitable for racing purpose in Nepal and to improve lateral stability of the vehicle.

\section{Front Impact Analysis}

The frontal impact is considered to be an elastic collision. The linear velocity remains $30 \mathrm{kmph}$ or $8.33 \mathrm{~m} / \mathrm{s}$ and weight of vehicle is $150 \mathrm{~kg}$. The value of force is calculated by the mass moment 
equation. Generally the collision takes place for very short duration of time. We assume this time to be $\Delta \mathrm{T}=1.01 \mathrm{~s}$. The following calculations are done in order to design the frame in the best way.

The momentum of the Vehicle at $30 \mathrm{kmph}$ is given by,

$P=W \times V$

$P=150 \times 8.33$

$P=1249.5 \mathrm{kgm} / \mathrm{s}$

And the frontal impact force is given by,

$F=\frac{P}{\Delta T}$

$F=\frac{1249.5}{1.01}$

$F=1237.13 \mathrm{~N}$

Therefore the impact force by speed limit is $1237.13 \mathrm{~N}$.

The trike will have maximum of $1 \mathrm{G}$ force under acceleration limit.

Therefore the impact force is given by,

$F=1 \times W \times a$

$F=1 \times 150 \times 9.81$

$F=1471.5 \mathrm{~N}$

The values of the force are practically comparable. According to a research the body has to pass $6.8 \mathrm{G}$ force for extreme worst case collision. Therefore for static frontal analysis the force is calculated as;

$F=6.8 \times W \times a$

$F=6.8 \times 220 \times 9.81$

$F=10006.2 \mathrm{~N}$

Therefore

The worst impact force $=1471.5+10006.2 \mathrm{~N}$

$$
=11477.7 \mathrm{~N}
$$

\section{Side Impact Analysis}

In the case of collision by side impact the value of impact force is calculated in the same way as in the case of frontal impact. For the side impact the velocity of the vehicle is taken as $48 \mathrm{kmph}$ or 13.33 $\mathrm{m} / \mathrm{s}$ according to ENCAP (The European New Car Assessment Program) standard [4] and hence the force is calculated as,

$F=\frac{P}{\Delta T}$

Where,

$\mathrm{P}=\mathrm{W} \times \mathrm{V}$

$=150 \times 13.33=1999.5 \mathrm{kgm} / \mathrm{s}$

The side impact force is given by,

$F=\frac{1999.5}{1.01}$

$F=1979.70 \mathrm{~N}$

Therefore the side impact force by speed limit is $1979.70 \mathrm{~N}$.

The trike will have maximum of $1.35 \mathrm{G}$ force under acceleration limits.

Therefore the impact force is given by,

$F=1.35 \times 150 \times 9.81$

$F=1986.525 \mathrm{~N}$

The values of the force are practically comparable.
According to a research the body has to pass $2 \mathrm{G}$ force for extreme worse case collision for side impact. Therefore for static side impact analysis, the force is calculated as,

$F=2 \times W \times a$

$F=2 \times 150 \times 9.81$

$F=2943 N$

Therefore

The worst impact force,

$F^{\prime}=1979.70+2943$

$F^{\prime}=4922.7 \mathrm{~N}$

\section{Rolling Resistance}

Rolling Resistance (RR) is the force necessary to propel a vehicle over a particular surface. The worst possible surface type to be encountered by the vehicle should be factored into the equation.

$R R=W \times C_{R R}$

$R R=150 \times 0.01$

$R R=1.5 \mathrm{~kg}$

\section{Grade Resistance}

Grade Resistance (GR) is the amount of force necessary to move a vehicle up a slope or grade. This calculation must be made using the maximum angle or grade the vehicle will be expected to climb in normal operation.

To convert incline angle, $\alpha$, to grade resistance:

$G R=W \times \sin \alpha$

$G R=150 \times \sin 2^{0}$

$G R=5.2 \mathrm{~kg}$

Acceleration Force

Acceleration Force $(\mathrm{Fa})$ is the force necessary to accelerate from a stop to maximum speed in a desired time.

$F_{a}=W \times V_{\max } \times \frac{1}{32.5 * t_{a}}$

$F_{a}=150 \times 27.34 \times \frac{1}{32.5 * 6}$

$F_{a}=21.03 \mathrm{~kg}$

\section{Total Tractive Effort}

The Total Tractive Effort (TTE) is the sum of the forces given below: (On higher speed vehicles friction in drive components may warrant the addition of $10 \%-15 \%$ to the total tractive effort to ensure acceptable vehicle performance.)
$T T E=R R+G R+F_{a}$
$T T E=1.5+5.2+21.03$
$T T E=27.73 \mathrm{~kg}$

\section{Wheel Motor Torque}

To verify the vehicle will perform as designed in regards to tractive effort and acceleration, it is necessary to calculate the required wheel torque (Tw) based on the tractive effort.

$T_{W}=T T E \times R_{W} \times R F$

$T_{W}=27.73 \times 0.34 \times 1.1$

$T_{W}=10.37 \mathrm{~kg} . \mathrm{m}$ 


\section{Reality Check}

The final step is to verify the vehicle can transmit the required torque from the drive wheel(s) to the ground. The maximum tractive torque (MTT) a wheel can transmit is equal to the normal load times the friction coefficient between the wheel and the ground times the radius of the drive wheel.

$M T T=W \times \mu \times R_{W}$

$M T T=150 \times 0.4 \times 0.34$

$M T T=20.4 \mathrm{~kg} \cdot \mathrm{m}$

\section{Interpreting Results:}

The Total Tractive Effort is the net horizontal force applied by the drive wheels to the ground. If the design has two drive wheels, the force applied per drive wheel (for straight travel) is half of the calculated TTE.

The Wheel Torque calculated is the total wheel torque. This quantity does not change with the number of drive wheels. The sum of the individual drive motor torques must be greater than or equal to the computed Wheel Torque.

The Maximum Tractive Torque represents the maximum amount of torque that can be applied before slipping occurs for each drive wheel. The total wheel torque calculated in must be less than the sum of the Maximum Tractive Torques for all drive wheels or slipping will occur.

\section{Critical Speed}

Characteristic speed is experience by understeer vehicle which is the speed at which the steer angle required to negotiate a turn is twice the Ackerman angle. While critical speed is associated with oversteer vehicle. It is the speed at the steer angle of a vehicle is zero and above which the vehicle become directionally unstable. It can be represented by the equation below:

Critical Speed,

$$
\begin{aligned}
& V_{C R}=\sqrt{-57.3 \frac{W B \times g}{K}} \\
& V_{C R}=\sqrt{-57.3 \frac{1.25 \times 9.81}{-1.34}} \\
& V_{C R}=25 \mathrm{~m} / \mathrm{s}
\end{aligned}
$$

\section{DESIGN AND ANALYSIS}

Computer-aided design (CAD) is the use of computer systems (or workstations) to aid in the creation, modification, analysis, or optimization of a design. By choosing the optimum mechanism for the leaning mechanism the CAD model of the device is created with suitable dimensions obtained through engineering drawing.

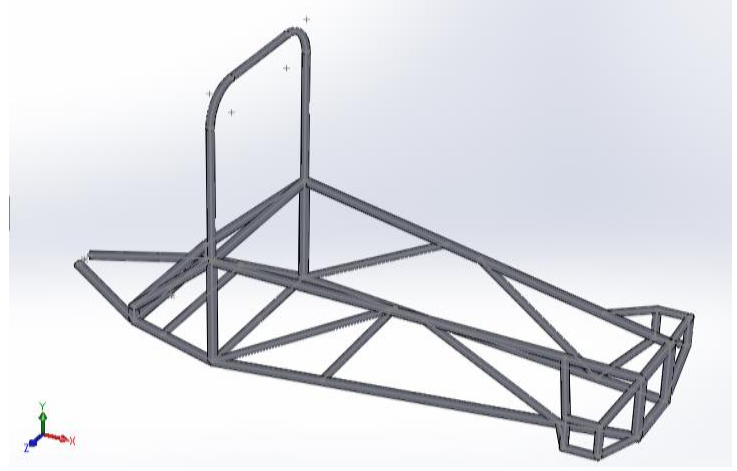

Fig. 1. Solid work design for chassis of tadpole configuration vehicle

Frame Safety Analysis was done using ANSYS R15.0 simulation where different theoretically calculated forces were used to see deformation of chassis under dynamic and static loading as well as during impact. The weight was measured $25 \mathrm{~kg}$ on software and static force due to engine and body weight of driver was taken to be $1300 \mathrm{~N}$.

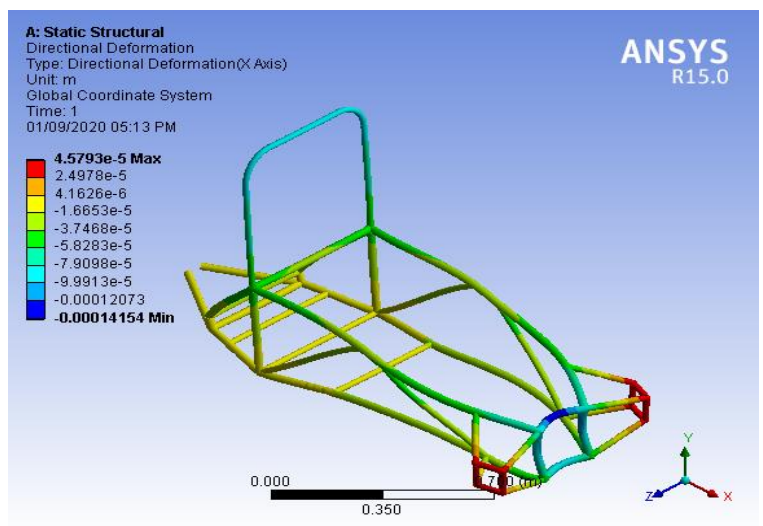

Fig.2. Front impact Analysis (Directional deformation)

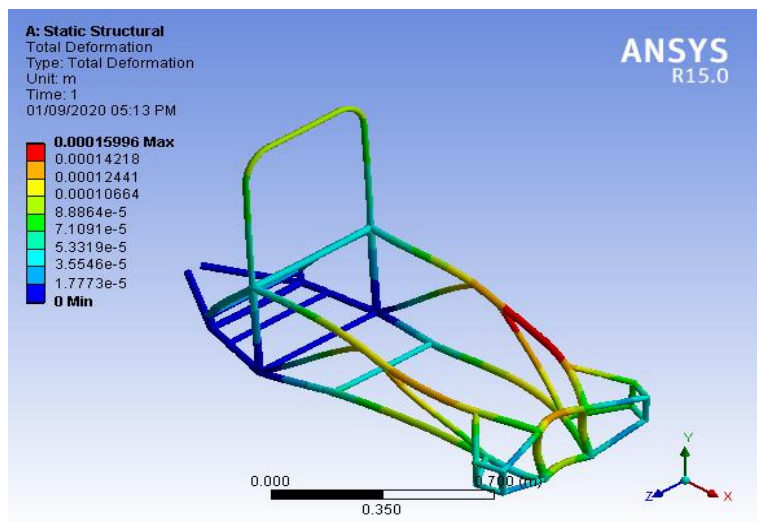

Fig.3. Front Impact Analysis (Total deformation) 


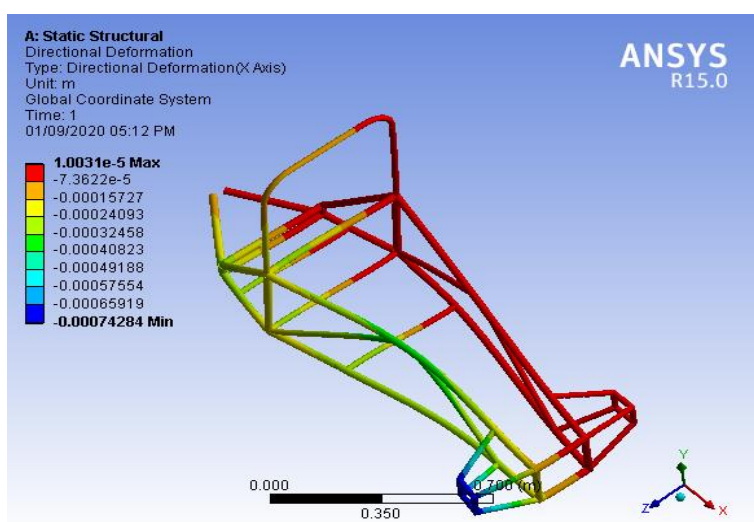

Fig.4. Side Impact Analysis (Directional deformation)

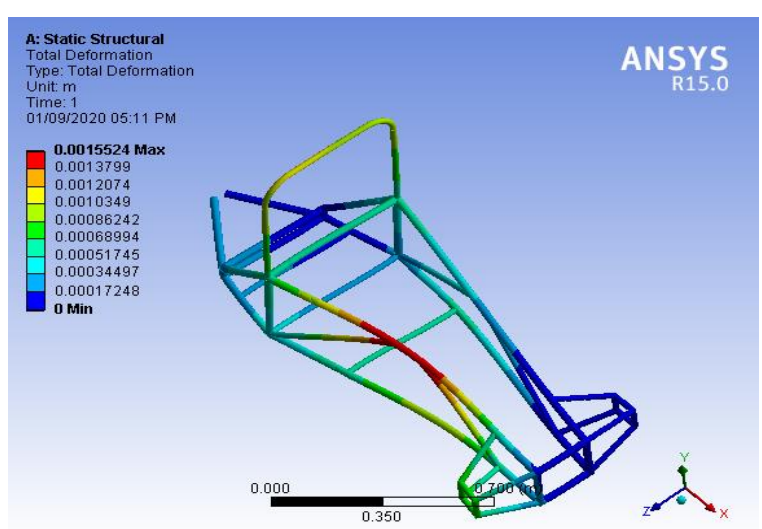

Fig.5. Side Impact Analysis (Total deformation)

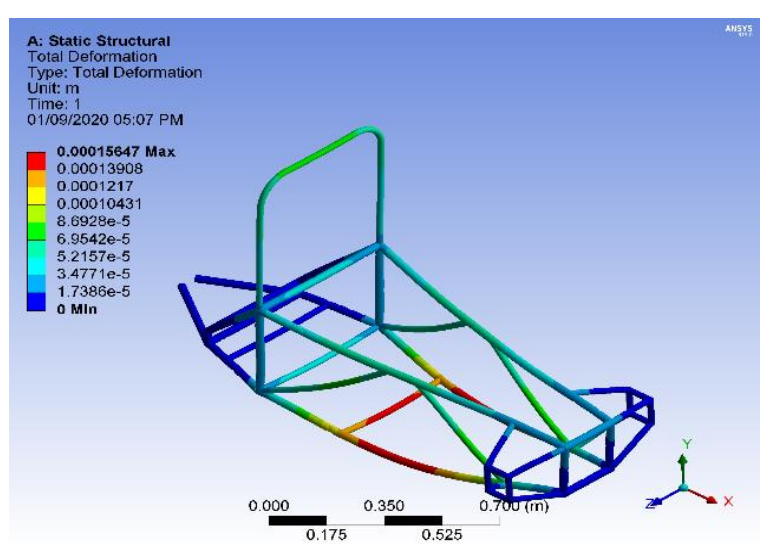

Fig.6. Total Deformation due to static loading

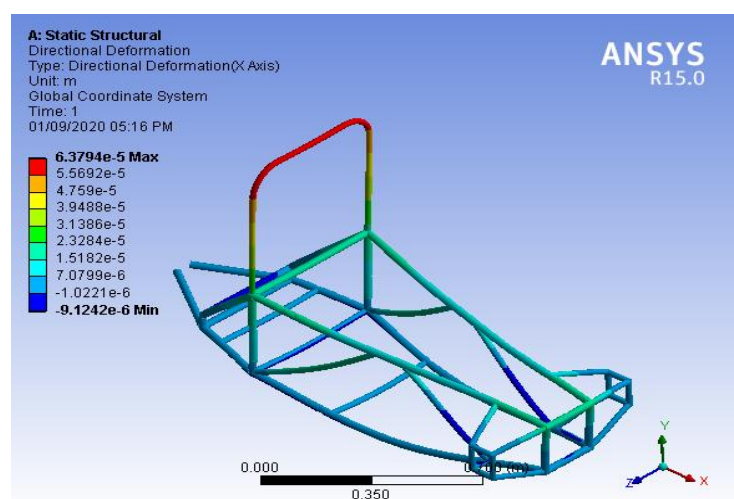

Fig.7. Directional Deformation due to static Loading

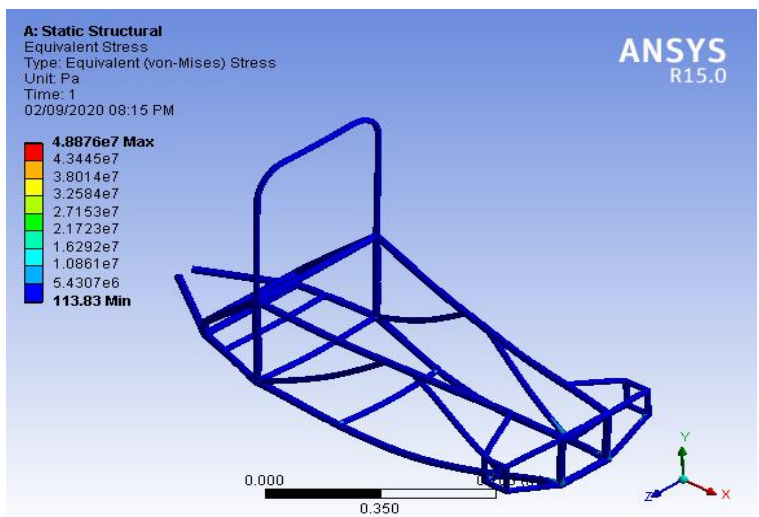

Fig.8.Von Mises stress for static loading

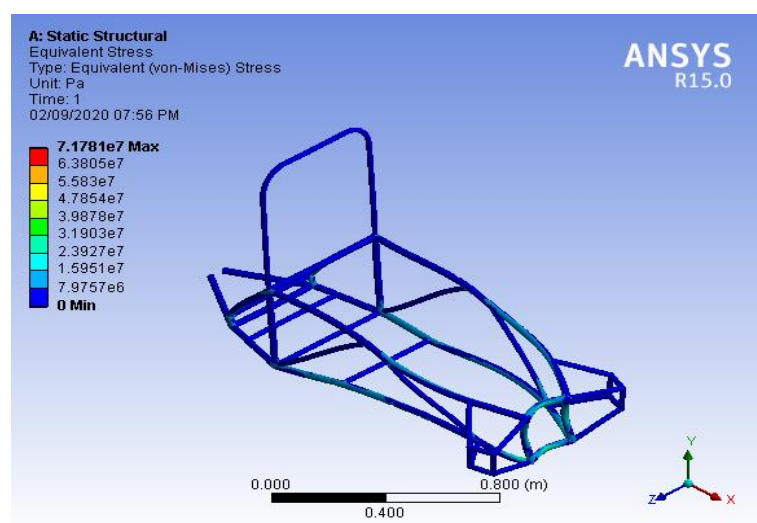

Fig.9.Von Mises stress for front loading 


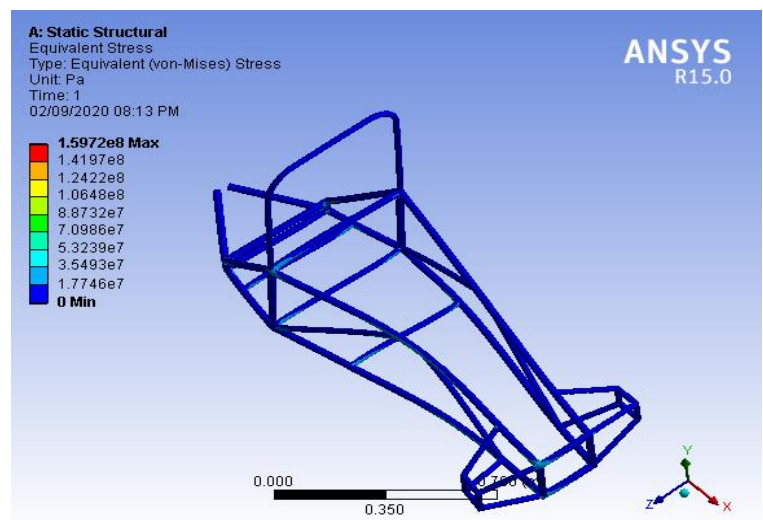

Fig 10. Von Mises stress for side loading

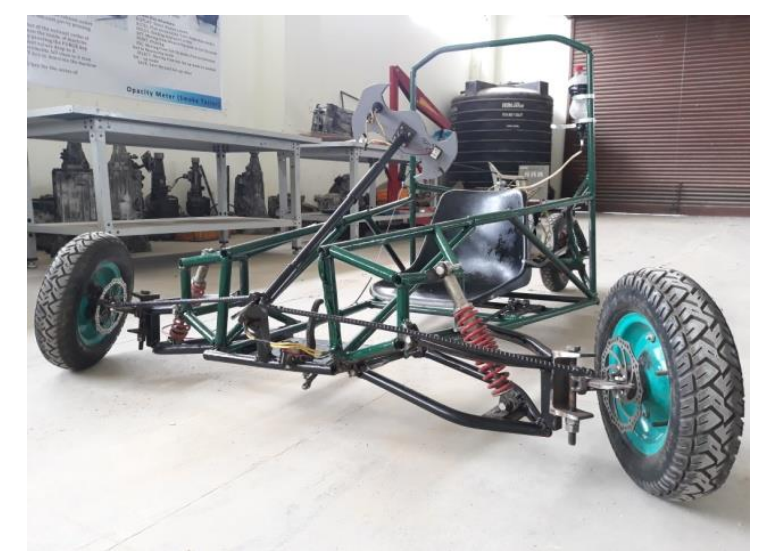

Fig 11. Fabricated Model of Trike

Table 1 summary of all analysis

\begin{tabular}{|c|c|c|c|}
\hline Parameter & $\begin{array}{l}\text { Directional } \\
\text { Deformation } \\
\text { (m) }\end{array}$ & $\begin{array}{l}\text { Total } \\
\text { Deformation } \\
\text { (m) }\end{array}$ & $\begin{array}{l}\text { Von } \\
\text { Mises } \\
\text { Stress } \\
\text { (pa) }\end{array}$ \\
\hline $\begin{array}{l}\text { Static } \\
\text { Loading }\end{array}$ & $\begin{array}{l}6.3794 \\
\times 10^{-5}\end{array}$ & $\begin{array}{l}1.5647 \\
\times 10^{-4}\end{array}$ & $\begin{array}{l}4.8876 \\
\times 10^{7}\end{array}$ \\
\hline $\begin{array}{l}\text { Front } \\
\text { Impact }\end{array}$ & $\begin{array}{l}4.5793 \\
\times 10^{-5}\end{array}$ & $\begin{array}{l}1.5996 \\
\times 10^{-4}\end{array}$ & $\begin{array}{l}7.1781 \\
\times 10^{7}\end{array}$ \\
\hline Side Impact & $\begin{array}{l}1.0031 \\
\times 10^{-5}\end{array}$ & $\begin{array}{l}1.5524 \\
\times 10^{-3}\end{array}$ & $\begin{array}{l}1.5972 \\
\times 10^{8}\end{array}$ \\
\hline
\end{tabular}

IV. Feasibility Study in context of Nepal To find out whether the study is feasible for Nepal or not, the financial analysis was done. They are done for both vehicle and race track to commercialize in market.

The annual interest rate, operational period and number of operational vehicle are $8 \%, 10$ years and 10 respectively. The table below shows the estimated information.

Table 2 Budget Estimation of Project

\begin{tabular}{|ll|}
\hline Particulars & Cost (NRP) \\
\hline Unit Vehicle Cost & $\mathbf{3 , 5 0 , 0 0 0}$ \\
Track Development & $\mathbf{3 5 , 0 0 , 0 0 0}$ \\
\hline
\end{tabular}

\begin{tabular}{|ll|}
\hline Annual Maintenance & $\mathbf{2 , 5 0 , 0 0 0}$ \\
Annual Rent & $\mathbf{3 , 0 0 , 0 0 0}$ \\
Annual Operational & $\mathbf{9 , 0 7 , 2 0 0}$ \\
Annual Benefit & $\mathbf{4 8 , 0 0 , 0 0 0}$ \\
\hline
\end{tabular}

Applying the B-C ratio method with an operational period of 10 years and MARR of $8 \%$ per year to determine the project should be extended or not.

\section{Conventional B-C ratio with PW:}

$$
\begin{gathered}
B-c=P W(B) /[I-P W(M V)+P W(O \& M)] \\
B-c=66,00,000(P / A, 8 \%, 20) /[70,00,000 \\
+14,57,200(P / A, 8 \%, 20)] \\
B-C=\mathbf{2 . 6 4}>1 ; \text { Feasible }
\end{gathered}
$$

Modified B-C ratio with PW:

$$
\begin{gathered}
B-C=[P W(B)-P W(O \& M)] /[I-P W(M V)] \\
B-C=[66,00,000(P / A, 8 \%, 20) \\
-1457200(P / A, 8 \%, 20)] \\
/ 70,00,000 \\
B-\boldsymbol{C}=\mathbf{3 . 2}>; \text { Feasible }
\end{gathered}
$$

Conventional B-C ratio with $\mathrm{AW}$ :

$$
\begin{gathered}
B-C=A W(B) /[C R+A W(O \& M)] \\
B-C=66,00,000 /[70,00,000(A / P, 8 \%, 20) \\
+14,57,200] \\
B-C=\mathbf{2 . 6}>1 ; \text { Feasible }
\end{gathered}
$$

Modified B-C ratio with AW:

$$
\begin{gathered}
B-C=[A W(B)-A W(O \& M)] / C R \\
B-C=[66,00,000-1457200] \\
/[70,00,000(A / P, 8 \%, 20)] \\
\boldsymbol{B}-\boldsymbol{C}=\mathbf{4 . 9}>1 ; \text { Feasible } \\
\text { V. CONCLUSION }
\end{gathered}
$$

\section{CONCLUSION}

The trike remains stable at speed below its critical speed due to increased track width. At its critical speed and beyond, the center of gravity of the vehicle falls behind the neutral steering point, such that the rear wheel slip angle will be larger than the front wheel which makes the static margin of the trike negative, hence the vehicle will respond to side load with a yawing motion. Also, the benefit to cost analysis of the vehicle and mid-range racing center also seems very promising, Moreover the craze for adventure among youths in Nepal for automobile and racing is exceptionally high. These vehicles can change the racing direction of Nepal in coming years.

\section{SUGGESTION FOR FUTURE STUDIES}

Several studies that can be carried out in the future to improve the accuracy and coherency of this work are listed below:

- Including rollover index to evaluate vehicle roll stability,

- Side slip angle-based controller could be developed to improve vehicle stability,

- Design of skid prevention system, 


\section{REFERENCES}

[1] Austin Ekuase (2015), Determination of Center of Gravity and Dynamic Stability Evaluation of a Cargo-type Tricycle, DOI: 10.12691/ajme-3-1-5, pp.26-31.

[2] Robertson, L.S, \& Kelly, A.B. (1988). "Static Stability as a Predictator of Overturn in Fatal Motor Vehicle Crashes," Journal of Trauma, 29(3), pp. 313-319.

[3] Rajamani R. (2006), Vehicle Dynamics and Control, DOI: 10.1007/0-378-28823-6

[4] T.S Rishi Govind, 2018, Design and Fabrication of All-Terrain Vehicle, Volume 5, Issue 4, IRJET. Pp.979-98

[5] Mukherjee, S.,Mohan, D., \& Gawade, T.R (2007). Three-Wheeled Scooter taxi: A safety analysis Sadhana, 32(4), pp. 459-478.

[6] Tiwari Vishnu Kant, Manish Srijan (2014), Quad Bike Design and Simulation: A PreManufacturing Methodology, Volume 5, Issue 6, pp.68-76.

[7] Khairna Gaurav (2017), Design of AutoTilting Mechanism, Volume 6, Issue 2, pp.416-419.

[8] N. A. El-Esnawy and J. F. Wilson,(2015) Lateral Dynamics and Stability of Two Vehicles in Tandem, Journal of Dynamics, Measurement, and Control, 120, pp. 51-56.

[9] P. S. Els, N. J. Theron, P. E. Uys, M. J. Thoresson, (2016) The Ride Comfort vs. Handling Compromise for Off-Road Vehicles, Journal of Terra mechanics, 44, pp. 303-317.

[10] L. Segel, (2007) On the Lateral Stability and Control of the Automobile as Influenced by Dynamics of the Steering System, Journal of Engineering for Industry, 88, pp. 283-294.

[11] M. K. Naidu, S. S. Rao, T. Tejesh, (2012) Ride Analysis of Three Wheeled Vehicle Using MATLAB/Simulink, AMAE International Journal on Manufacturing and Material Science, 2, pp. 22-26.

[12] Metu C., Aduloju S.C., Bolarinwa G.O., Olenyi J., Dania D. E. (2014). Vehicle Body Shape Analysis of Tricycles for Reduction in Fuel Consumption. Innovative System Design and Engineering 5(11) ,pp. 91-99. 